\title{
Gender Difference in Circulatory Associated Multi-Morbidity among the Elderly in Rural Southwest China
}

\author{
Huixin $\mathrm{Wu}^{1}$, Le Cai ${ }^{1}$, Wenlong Cui ${ }^{*}$, Ying Song1, \\ Chenghuan Sun1, Yao Yang' , Jianhui He ${ }^{1}$ \\ ${ }^{1}$ School of Public Health, Kunming Medical University, Kunming, China \\ ${ }^{2}$ Graduate school, Kunming Medical University, Kunming, China \\ Email: *cuiwenlong972@126.com
}

How to cite this paper: Wu, H.X., Cai, L., Cui, W.L., Song, Y., Sun, C.H., Yang, Y. and He, J.H. (2021) Gender Difference in Circulatory Associated Multi-Morbidity among the Elderly in Rural Southwest China. Journal of Biosciences and Medicines, 9, 127-136.

https://doi.org/10.4236/jbm.2021.96012

Received: September 8, 2020

Accepted: June 15, 2021

Published: June 18, 2021

Copyright $\odot 2021$ by author(s) and Scientific Research Publishing Inc. This work is licensed under the Creative Commons Attribution International License (CC BY 4.0).

http://creativecommons.org/licenses/by/4.0/

(c) (i) Open Access

\begin{abstract}
Aim: This study examined the prevalence of four chronic circulatory system diseases (hypertension, CHD, hyperlipemia, Stroke) and associated multi-morbidity in order to identify the risk factors among the elderly in Yunnan province. Methods: A cross-sectional survey including 2299 consenting adults aged $\geq 60$ years from rural places was conducted in 2018. Data of demographic parameters and clinical characteristics were acquired from questionnaire and health examination. Categorical variables were presented as counts and percentages. Multivariable logistic regression analysis was used to analyze the association between individual SES and lifestyle variables and multimorbidity of the four chronic cardiovascular and cerebrovascular diseases. All analyses were conducted with SPSS 17.0 software. Results: Our study suggested that the prevalence of hypertension, CHD, hyperlipemia, Stroke was $57.1 \%, 4.2 \%, 5.9 \%$ and $5.3 \%$, respectively and the prevalence of multimorbidity was $10.3 \%$. Females had a higher prevalence of family history of chronic cardiovascular and cerebrovascular diseases, obesity, central obesity and illiteracy than males $(\mathrm{P}<0.01)$, whereas males had a markedly higher prevalence of drinking, smoking and good sleeping quality than females $(\mathrm{P}<$ $0.01)$. The family genetic history, obesity, smoking, education, and diabetes were positively and drinking was negatively correlated with the prevalence of circulatory associated multimorbidity in elderly. Interestingly, some of the above associations were only observed in male/female but not the other sex. Conclusions: The prevalence of circulatory disease associated multimorbidity is relatively high among elderly population in rural places of Yunan province and the risk factors are different between females and males.
\end{abstract}




\section{Keywords}

Gender Difference, Circulatory Diseases, Multi-Morbidity, Older Adults, Prevalence

\section{Introduction}

According to the China National Bureau of Statistics, there were 249 million people aged $\geq 60$ years ( $17.9 \%$ of the total population) in 2018 which will increase to 480 million ( $34.1 \%$ of the total population) by the middle of the 21 st century [1].

In response to this particular demographic change, the international community proposed that "elderly women" should be regarded as a special group of population who requiring special attention [2].

The World Health Organization has reported that Chronic non-communicable diseases (NCDs) will be the leading causes of death by 2030. In China, a previous study indicated the prevalence of NCDs associated multi-morbidity among population aged $\geq 60$ years ranged from $6.4 \%$ to $76.5 \%$ and the prevalence was higher in urban areas compared to rural places [3] [4] [5].

Brandlmeier pointed out in 1976 that the concept of multi-morbidity was not specific and could be easily confused by researchers and doctors which eventually lead to inconsistencies and incomparability between research results. Therefore, the term "Multimorbidity" was proposed and defined as "acute or chronic diseases coexisting in one body" [6].

Similarly, multimorbidity was defined in the context of health care as a remedy to single disease which demands the universalize in the clinical management. Much of current research did not specified the chronic NCD type and different diseases may act synergistically in disease progression.

In 2008, WHO formally defined multimorbidity as the presence of 2 or more chronic diseases in one patient [7].

Previous studies on chronic diseases of the elderly showed that the incidence of multimorbidity increased with age. Under the circumstances of accelerated population aging in China, the problem of elderly people's comorbidity has gradually become more and more critical. Therefore, it is important to depict the demographics parameters and clinical characteristics among elderly and more importantly, to explore the risk factor for NCD associated multimorbidity.

\section{Methods}

\subsection{Disease Definitions}

Hypertension: currently taking antihypertensive drugs; clear disease history diagnosed at tertiary hospital or above; diastolic blood pressure $\geq 90 \mathrm{mmHg}$ and/or Systolic blood pressure $\geq 140 \mathrm{mmHg}$ upon admission. An average of the three $\mathrm{BP}$ readings was recorded as the $\mathrm{BP}$ level in this study. 
Diabetes: currently taking diabetic treatment; clear disease history diagnosed at tertiary hospital or above; blood glucose $\geq 11.1 \mathrm{mmol} / \mathrm{L}$ at 2 hours after meal; or fasting blood glucose $\geq 7.0 \mathrm{mmol} / \mathrm{L}$.

Multi-morbidity: being diagnosed with at least 2 chronic diseases out of the five common circulatory diseases.

Body mass index (BMI) was calculated as weight $(\mathrm{kg})$ divided by height squared $\left(\mathrm{m}^{2}\right)$. Obesity was defined as BMI $\geq 28 \mathrm{~kg} / \mathrm{m}^{2}$.

Central obesity was defined as a waist circumference $\geq 90 \mathrm{~cm}$ in males and $\geq 80$ $\mathrm{cm}$ in females, respectively, according to $\mathrm{WHO}$ recommendations for Asian adults.

\subsection{Study Area and Population}

A cross-sectional survey was conducted in 2018 in Yunnan Province, China. Multi-stage stratified random sampling was used to extract the research objects. Firstly, 129 counties in Yunnan Province were divided into two groups according to per capita gross national product (GDP) based on the 2017 Yunnan Statistical Yearbook: economically advanced and disadvantaged. Secondly, each county was further classified into two groups based on per capita GDP. Thirdly, the probability proportional to size (PPS) was used to select 5 administrative villages from each of the selected townships. Finally, the method of simple random sampling was used to carry out in household survey in 10 villages, and all rural residents aged $\geq 60$ years from the village committee and above were included in the survey.

The sample size was calculated by Power Analysis \& Sample Size (PASS) software.

In this study, we selected the prevalence of multi-morbidity in the elderly. By consulting the literature, we found that the prevalence of multi-morbidity ranged from $6.4 \%$ to $76.5 \%$, so we used $12 \%$ in our study.

\subsection{Data Selection}

A self-designed questionnaire was used and a one-to-one interview was conducted by trained and qualified investigators after receiving the consents from the respondents. The contents of the questionnaire including: demographic parameters such as gender, nationality, family income, age, whether there is toilet in the family, time needed to walk to the nearest medical institution, behavior and life style (smoking, drinking, vegetable, meat), family history of cardiovascular and cerebrovascular diseases, etc.

Information on lifestyle factors, demographic characteristics, individual socioeconomic status (SES), diagnosis and self-reported family history was obtained as well as BP, FBG and anthropometric measurements. Three consecutive BP measurements were obtained using a sphygmomanometer following American Heart Association recommendations. The average of the three BP readings was recorded as the BP level in this study. FBG was measured in the morning following the ACCUCHEK Performa glucometer (Roche Diagnostics, Germany). A small drop of fingertip blood was taken from each participant after an 
overnight fast of at least $10 \mathrm{~h}$. Height, weight and waist and hip circumference were determined by a standardized protocol to ensure the highest accuracy.

\subsection{Statistical Analysis}

SPSS 17.0 was used for statistical analysis. The data was presented as percentage and the inter-group comparison was evaluated by Chi square test. The nationality, obesity, central obesity, family history, smoking, education, level poverty, drinking and diabetes were identified as independent variable with the multimorbidity of 5 common circulatory diseases as dependent variables. The relationship was analyzed by non-conditional logistic regression with multi-model adjustment. The assignment of variables was shown in Table 1 . In order to

Table 1. Socioeconomic and lifestyle characteristics among participants [n (\%)].

\begin{tabular}{|c|c|c|c|}
\hline Characteristic & Male $(n=1100)$ & Female $(n=1199)$ & All $(n=2299)$ \\
\hline \multicolumn{4}{|l|}{ Age } \\
\hline $60-64$ years & $306(27.8)$ & $382(31.9)$ & $688(29.9)$ \\
\hline $65-69$ years & $315(28.6)$ & $307(25.6)$ & $622(27.1)$ \\
\hline 70 - 74 years & $229(20.8)$ & $241(20.1)$ & $470(20.4)$ \\
\hline$\geq 75$ years & $250(22.7)$ & $269(22.4)$ & $519(22.6)$ \\
\hline \multicolumn{4}{|l|}{ Ethnicity (\%) } \\
\hline Han & $617(56.1)$ & $642(53.5)$ & $1259(54.8)$ \\
\hline Minority & $483(43.9)$ & $557(46.5)$ & $1040(45.2)$ \\
\hline \multicolumn{4}{|l|}{ Education (\%) } \\
\hline Illiterate & $749(68.1)$ & $1056(88.1)^{* *}$ & $1805(78.5)$ \\
\hline Primary or higher & $351(31.9)$ & $143(11.9)$ & $494(21.5)$ \\
\hline Impoverished $(\%)$ (per net income $<333.3 \$$ ) & $110(10.0)$ & $146(12.2)$ & $256(11.1)$ \\
\hline Smoker (\%) & $851(77.4)$ & $45(3.8)^{\star *}$ & $896(39.0)$ \\
\hline Drinker (\%) & $321(29.2)$ & $25(2.1)^{\star \star}$ & $346(15.1)$ \\
\hline White meat & $310(28.2)$ & $353(29.4)$ & $663(28.8)$ \\
\hline \multicolumn{4}{|l|}{ Sleep } \\
\hline Good & $626(56.9)$ & $468(39.0)^{* *}$ & $1094(47.6)$ \\
\hline Poor & $474(43.1)$ & $731(61.0)$ & $1205(52.4)$ \\
\hline \multicolumn{4}{|l|}{ Family history of NCD } \\
\hline Hypertension & $114(10.4)$ & $200(16.7)^{\star *}$ & $314(13.7)$ \\
\hline Stroke & $16(1.5)$ & $29(2.4)$ & $45(2.0)$ \\
\hline coronary heart disease & $21(1.9)$ & $38(3.2)$ & $59(2.6)$ \\
\hline Hyperlipemia & $13(1.2)$ & $18(1.5)$ & $31(1.3)$ \\
\hline Mean BMI & $22.8 \pm 3.3$ & $23.2 \pm 3.7$ & $23.0 \pm 3.5$ \\
\hline Overweight (\%) & $268(24.4)$ & $338(28.2)^{\star *}$ & $606(26.4)$ \\
\hline Obesity (\%) & $75(6.8)$ & $121(10.1)^{\star *}$ & $196(8.5)$ \\
\hline Mean waist circumference & $83.0 \pm 9.2$ & $83.6 \pm 10.0$ & $83.3 \pm 9.7$ \\
\hline Central obesity & $476(43.3)$ & $794(66.2)^{* *}$ & $1270(55.2)$ \\
\hline
\end{tabular}

${ }^{*} \mathrm{P}<0.05,{ }^{*} \mathrm{P}<0.01$ 
reduce the impact of confounding factors on the association between central obesity and various chronic diseases, the basic characteristics, physical examination, lifestyle and disease status were included in the model. A p value less than 0.01 was considered as statistically significant.

\section{Results}

2299 individuals aged $\geq 60$ years responded in total of 2400 surveyed people. The response rate of elder rural people was $95.8 \%$. Among them, 1199 (52.2\%) rural residents were female and $1100(47.8 \%)$ people were male.

Females had a higher prevalence of family history of chronic circulatory diseases, obesity, central obesity and illiteracy than males $(\mathrm{P}<0.01)$, whereas males had a markedly higher prevalence of drinking, smoking and good sleeping than females $(\mathrm{P}<0.01)$.

The prevalence of multimorbidity was $10.3 \%$. The overall prevalence of hypertension, CHD, hyperlipemia, Stroke was $57.1 \%, 4.2 \%, 5.9 \%$ and $5.3 \%$ respectively.

Table 2 and Table 3 presented the distribution of chronic circulatory diseases and multi-morbidity by individual SES and lifestyle factors

Table 2. Prevalence of chronic cardiovascular and cerebrovascular diseases and multi-morbidity among female older adults in rural Yunnan Province[n (\%)].

\begin{tabular}{|c|c|c|c|c|c|c|c|}
\hline \multirow{2}{*}{ Characteristic } & \multirow{2}{*}{ Hypertension } & \multirow{2}{*}{ Stroke } & \multirow{2}{*}{ CHD } & \multirow{2}{*}{ Hyperlipemia } & \multicolumn{3}{|c|}{ Number of multi-morbidity } \\
\hline & & & & & 0 & 1 & $\geq 2$ \\
\hline \multicolumn{8}{|l|}{ Age } \\
\hline $60-64$ years & $196(51.3)$ & $15(3.9)$ & $14(3.7)$ & $31(8.1)$ & $167(43.7)$ & $179(46.9)$ & $36(9.4)$ \\
\hline $65-69$ years & $167(54.4)$ & $15(4.9)$ & $11(3.6)$ & $25(8.1)$ & $128(41.7)$ & $144(46.9)$ & $35(11.4)$ \\
\hline 70 - 74 years & $152(63.1)$ & $15(6.2)$ & $8(3.3)$ & $17(7.1)$ & $79(32.8)$ & $134(55.6)$ & $28(11.6)$ \\
\hline$\geq 75$ years & $165(61.3)$ & $12(4.5)$ & $11(4.1)$ & $11(4.1)$ & $101(37.5)$ & $139(51.7)$ & $29(10.8)$ \\
\hline \multicolumn{8}{|l|}{ Ethnicity (\%) } \\
\hline Han & $386(60.1)^{* *}$ & $43(6.7)^{\star *}$ & $21(3.3)$ & $65(10.1)^{\star \star}$ & $227(35.4)$ & $325(50.6)$ & $90(14.0)^{* *}$ \\
\hline Minority & $294(52.8)$ & $14(2.5)$ & $23(4.1)$ & $19(3.4)$ & $248(44.5)$ & $271(48.7)$ & $38(6.8)$ \\
\hline \multicolumn{8}{|l|}{ Education (\%) } \\
\hline Illiterate & $301(56.2)$ & $21(3.9)$ & $16(3.0)$ & $28(5.2)^{\star \star}$ & $218(40.7)$ & $272(50.7)$ & $46(8.6)^{\star \star}$ \\
\hline Primary or higher & $379(57.2)$ & $36(5.4)$ & $28(4.2)$ & $56(8.4)^{\star *}$ & $257(38.8)$ & $324(48.9)$ & $82(12.4)^{* *}$ \\
\hline $\begin{array}{c}\text { Impoverished (\%) (per net } \\
\text { income }<333.3 \$)\end{array}$ & $87(59.6)$ & $10(6.8)$ & $4(2.7)$ & $9(6.2)$ & $54(37.0)$ & $75(51.4)$ & $17(11.6)$ \\
\hline Smoker (\%) & $33(73.3)^{\star \star}$ & $5(11.1)$ & $12(26.7)^{\star \star}$ & $3(6.7)$ & $12(26.7)$ & $19(42.2)$ & $14(31.1)^{\star \star}$ \\
\hline Drinker (\%) & $14(56.0)$ & $0(0.0)$ & $1(4.0)$ & $1(4.0)$ & $11(44.0)$ & $13(52.0)$ & $1(4.0)$ \\
\hline Obesity (\%) & $90(74.4)^{\star \star *}$ & $8(6.6)$ & $6(5.0)$ & $16(13.2)^{\star \star}$ & $26(21.5)$ & $71(58.7)$ & $24(18.8)^{* \star}$ \\
\hline \multirow[t]{2}{*}{ Central obesity (\%) } & $504(63.5)^{* *}$ & $39(4.9)$ & $33(4.2)$ & $26(5.5)^{\star *}$ & $255(32.1)$ & $436(54.9)$ & $103(13.0)^{* *}$ \\
\hline & $680(56.7)$ & $57(4.8)$ & $44(3.7)$ & $84(7.0)$ & 475 (39.6) & $596(49.7)$ & $128(10.7)$ \\
\hline
\end{tabular}

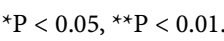


Table 3. Prevalence of chronic cardiovascular and cerebrovascular diseases and multimorbidity among male older adults in rural Yunnan Province[n (\%)].

\begin{tabular}{|c|c|c|c|c|c|c|c|}
\hline \multirow{2}{*}{ Characteristic } & \multirow{2}{*}{ Hypertension } & \multirow{2}{*}{ Stroke } & \multirow{2}{*}{ CHD } & \multirow{2}{*}{ Hyperlipemia } & \multicolumn{3}{|c|}{ Number of multimorbidity } \\
\hline & & & & & 0 & 1 & $\geq 2$ \\
\hline \multicolumn{8}{|l|}{ Age } \\
\hline $60-64$ years & $168(54.9)$ & $18(5.9)$ & $16(5.2)$ & $18(5.9)$ & $119(38.9)$ & $157(51.3)$ & $30(9.8)$ \\
\hline 65 - 69 years & $172(54.6)$ & $15(4.8)$ & $13(4.1)$ & $12(3.8)$ & $135(42.9)$ & $150(47.6)$ & $30(9.5)$ \\
\hline 70 - 74 years & $148(64.6)$ & $17(7.4)$ & $12(5.2)$ & $15(6.6)$ & $68(29.7)$ & $134(58.5)$ & $27(11.8)$ \\
\hline$\geq 75$ years & $144(57.6)$ & $15(6.0)$ & $12(4.8)$ & $7(2.8)$ & $96(38.4)$ & $133(53.2)$ & $21(8.4)$ \\
\hline \multicolumn{8}{|l|}{ Ethnicity (\%) } \\
\hline Han & $344(55.8)$ & $44(7.1)^{\star}$ & $25(4.1)$ & $35(5.7)$ & $237(38.4)$ & $318(51.5)$ & $62(10.0)$ \\
\hline Minority & $288(59.6)$ & $21(4.3)$ & $28(5.8)$ & $17(3.5)$ & $181(37.5)$ & $256(53.0)$ & $46(9.5)$ \\
\hline \multicolumn{8}{|l|}{ Education (\%) } \\
\hline Illiterate & $87(54.0)$ & $9(5.6)$ & $6(3.7)$ & $6(3.7)$ & $63(39.1)$ & $91(56.5)$ & $7(4.3)$ \\
\hline Primary or higher & $545(58.0)$ & $56(6.0)$ & $47(5.0)$ & $46(4.9)$ & $355(37.8)$ & $483(51.4)$ & $101(10.8)$ \\
\hline $\begin{array}{l}\text { Impoverished (\%) (per } \\
\text { net income }<333.3 \$ \text { ) }\end{array}$ & $68(61.8)$ & $6(5.5)$ & $4(3.6)$ & $6(5.5)$ & $35(31.8)$ & $67(60.9)$ & $8(7.3)$ \\
\hline Smoker (\%) & $502(59.0)^{\star *}$ & $58(6.8)^{\star *}$ & $51(6.0)^{* *}$ & $41(4.8)$ & $310(36.4)$ & $441(51.8)$ & $100(11.8)^{\star *}$ \\
\hline Drinker (\%) & $184(57.3)$ & $12(3.7)$ & $7(2.2)^{* *}$ & $14(4.4)$ & $126(39.3)$ & $175(54.5)$ & $20(6.2)^{\star *}$ \\
\hline Obesity (\%) & $52(69.3)^{\star *}$ & $9(12.0)$ & $4(5.3)$ & $7(9.3)^{*}$ & $20(26.7)$ & $39(52.0)$ & $16(21.3)^{\star *}$ \\
\hline \multirow[t]{2}{*}{ Central obesity (\%) } & $323(67.9)^{* *}$ & $34(7.1)$ & $27(5.7)$ & $26(5.5)$ & $128(26.9)$ & $291(61.1)$ & $57(12.0)^{*}$ \\
\hline & $632(57.5)$ & $65(5.9)$ & $53(4.8)$ & $52(4.7)$ & $418(38.0)$ & $574(52.2)$ & $108(9.8)$ \\
\hline
\end{tabular}

${ }^{*} \mathrm{P}<0.05,{ }^{*} \mathrm{P}<0.01$.

In Table 2, the prevalence of hypertension, CHD, hyperlipemia, Stroke among female older adults was $56.7 \%, 3.7 \%, 7.0 \%$ and $4.8 \%$, respectively, and the prevalence of multi-morbidity was $10.7 \%$. Our data suggested that Han ethnicity had a higher prevalence of hypertension, hyperlipemia and Stroke as well as multi-morbidity compared to minorities in female $(\mathrm{P}<0.01)$. Older adults with higher education had a higher prevalence of hyperlipemia and multi-morbidity compared to their counterparts $(\mathrm{P}<0.01)$. Female smokers had a higher prevalence of hypertension, CHD and multi-morbidity than non-smoker $(\mathrm{P}<0.01)$. Older women with obesity or central obesity had a higher prevalence of hypertension, CHD and multi-morbidity $(\mathrm{P}<0.01)$.

In Table 3, the prevalence of hypertension, CHD, hyperlipemia, Stroke among males was $57.5 \%, 4.8 \%, 4.7 \%$ and $5.9 \%$, respectively, and the prevalence of multi-morbidity was $9.8 \%$. In addition, our data suggested the prevalence was associated with age in males.

Among male population, Han ethnicity had a higher prevalence of hypertension, hyperlipemia and Stroke than the other minorities $(\mathrm{P}<0.01)$. Older educated men had a higher prevalence of hyperlipemia and multimorbidity than 
their counterparts $(\mathrm{P}<0.01)$. Male smokers and drinkers had a higher prevalence of hypertension, $\mathrm{CHD}$ and multimorbidity than their counterparts $(\mathrm{P}<$ 0.01)

The prevalence of hypertension, $\mathrm{CHD}$ and multimorbidity were higher among elderly men with obesity or central obesity $(\mathrm{P}<0.05)$.

Multivariate logistic regression analysis was then applied to determine whether the multimorbidity was the dependent variable $(0=$ no, $1=$ yes $)$. After controlling the age (age), variables were defined as following: nationality $(0=$ Han, 1 = minority $)$, obesity $(0=$ no, $1=$ yes $)$, sex $(0=$ male, $1=$ female $)$, smoking $(0=$ no, $1=$ yes $)$, drinking $(0=$ no, $1=$ yes $)$, family history of chronic diseases $(0=$ no, $1=$ yes $)$, education level $(0=$ uneducated, $1=$ educated $)$, poverty $(0=$ no, $1=$ yes), diabetes $(0=$ no, $1=$ yes $)$, physical exercise $(0=$ lack, $1=$ rich $)$, vegetable oil $(0=$ no, $1=$ yes $)$, egg $(0=$ lack, $1=$ rich $)$, milk $(0=$ lack, $1=$ rich $)$, White meat $(0$ = lack, $1=$ rich $)$, Pickles $(0=$ lack, $1=$ rich $)$,fried food $(0=$ lack, $1=$ rich $)$ and salt $(0=$ light, $1=$ heavy) before analyzing the association between multimorbidity and various risk factors in men and women.

In Table 4, the results showed that the family genetic history, obesity, smoking, education, and diabetes were positively and drinking was negatively correlated with the prevalence of circulatory associated multimorbidity in elderly. Interestingly, some of the above associations were only observed in male/female but not the other sex.

\section{Discussion}

CVDs are a group of disease that was affected by age and numerous genetic as well as environmental factors. It has been speculated that nutrition deficiency and/or imbalance are important contributors to the pathogenesis of CVDs [8]. This is study was conducted in rural places with limited household income where nutrition deficiency and/or imbalance is more commonly seen. Compared to a previous Chinese systematic review, the prevalence of multi-morbidity in older persons aged $\geq 60$ years ranged from $6.4 \%$ to $76.5 \%$ [5], and the prevalence

Table 4. Survey logistic regression for multi-morbidity of chronic circulatory diseases.

\begin{tabular}{ccccccc}
\hline & \multicolumn{3}{c}{ Female } & & \multicolumn{3}{c}{ Male } \\
\cline { 2 - 7 } & $\mathbf{P}$ & Exp (B) & 95\%CI & P & Exp (B) & 95\%CI \\
\hline Drinking (reference: no drink) & 0.569 & 0.536 & $(0.063,4.575)$ & 0.017 & 0.491 & $(0.274,0.882)$ \\
Smoking (reference: no smoke) & 0.000 & 6.936 & $(3.203,15.020)$ & 0.000 & 5.349 & $(2.369,12.074)$ \\
Diabetes (reference: no diabetes) & 0.204 & 1.411 & $(0.830,2.401)$ & 0.003 & 2.435 & $(1.366,4.341)$ \\
Education (reference: illiterate) & 0.045 & 1.537 & $(1.009,2.342)$ & 0.074 & 2.114 & $(0.931,4.801)$ \\
family history (reference: no inheritance) & 0.012 & 1.784 & $(1.133,2.810)$ & 0.022 & 1.955 & $(1.103,3.466)$ \\
Obesity (reference: no obesity) & 0.000 & 1.793 & $(1.346,2.389)$ & 0.001 & 1.745 & $(1.254,2.427)$ \\
Fried food (reference: few fried food) & 0.028 & 0.625 & $(0.412,0.949)$ & 0.079 & 0.639 & $(0.388,1.053)$ \\
HAN nationality (reference: other) & 0.000 & 2.887 & $(1.749,4.767)$ & 0.201 & 1.420 & $(0.829,2.434)$ \\
\hline
\end{tabular}


of multi-morbidity of 5 NCDs was $16.1 \%$ in another rural study [9]. The prevalence of multi-morbidity of 5 chronic circulatory diseases in our study was relatively low (10.3\%), excluding other chronic diseases.

The prevalence of chronic circulatory multi-morbidity diseases was different in males and females. Our data suggested that the prevalence of NCD among females from Han ethnicity was $14.0 \%$ which was higher than other minorities. Gender-related factors are those influenced by the cultural and psychological habits, while sex-related factors are linked to biological traits and functional features. In general, the number of women with multi-morbidity was significantly higher than that of men [10]. While the prevalence of the NCDs was lower in female. The existence of gender disparities

in the diagnosis and treatment of cardiovascular diseases has been discussed previously [11] which indicating that compared to male, females are more often to suffer from delayed treatment. Results of this study suggested that these disparities may be even higher among elderly population.

The dietary pattern is often very rich in bioactive compounds such as unsaturated fatty acids, polyphenols, fiber, phytosterols, vitamins and minerals, which may exert antioxidant, anti-inflammatory and anti-thrombotic effects that contributing to the delay of CVD initiation and progression [12]. Stock EO found HDL levels were elevated in the 3 most common types of hyperlipidemia [13]. Stroke, heart disease, dyslipidemia were identified as most common contributors for multi-morbidity among elderly residents in China [14].

Roeters et al. found that many of the circulatory diseases risk factors, diabetes, high-density lipoprotein (HDL) levels and triglyceride were more commonly observed among women compared to men [15]. Our study indicated that ethnicity was significantly associated with the prevalence of circulatory disease in the elderly women. Generally speaking, females from minorities were associated with the lowest incidence of NCD, which might be explained by their preference to consume white meat and exercise more. Our results suggested that, different strategies should be adopted during health education.

Our study proved that women and men have different risk factors for circulatory associated multi-morbidity and different strategies should be adopted during health education.

\section{Limitations of This Study}

The findings of the present study are limited in several ways. First, the prevalence of hypertension, CHD, hyperlipemia, Stroke was based on self-reporting. Given that some patients without access to quality healthcare may not be aware of their status, the prevalence of target diseases and multimorbidity in this study may be underestimated. Second, some elderly adults invited to participate in the study could not do so due to illness or hospitalization as a result of their NCDs. This may have translated into an underestimation of the prevalence of NCDs. Finally, the present results were based on a study of two counties, which may 
limit the ability to generalize the results to the whole province, despite the randomized sampling method undertaken.

\section{Funding}

The data collection and analysis of this study was supported by grants from Union Specific Project Foundation of Yunnan Provincial Science and Technology Department and Kunming Medical University (2018FE001(-014)), and Innovative Research Team of Yunnan Province (202002AE160002).

\section{Ethical Approval}

Prior to carrying out this research, this study was approved by the Ethics Committee of Kunming Medical University.

\section{Availability of Data and Materials}

The datasets used and/or analyzed during the current study are available from the corresponding author on reasonable request.

\section{Conflicts of Interest}

The authors declare no conflicts of interest regarding the publication of this paper.

\section{References}

[1] National Bureau of Statistics of China (2019) Statistical Communiqué of the People's Republic of China on the 2018 National Economic and Social Development. National Bureau of Statistics of China, Beijing.

[2] Chinese Women's Movement (2007) Research Report on the Prediction of the Trend of the Aging Population in China. Chinese Women's Movement, 2, 15-18.

[3] Hu, X., Huang, J., Lv, Y., et al. (2015) Status of Prevalence Study on Multimorbidity of Chronic Disease in China: Systematic Review. Geriatrics \& Gerontology International, 15, 1-10. https://doi.org/10.1111/ggi.12340

[4] Gu, J., Chao, J., Chen, W., et al. (2017) Multimorbidity in the Community Dwelling Elderly in Urban China. Archives of Gerontology and Geriatrics, 68, 62-67. https://doi.org/10.1016/j.archger.2016.09.001

[5] Agborsangaya, C.B., Lau, D., Lahtinen, M. et al. (2012) Multimorbidity Prevalence and Patterns Across Socioeconomic Determinants: A Cross Sectional Survey. BMC Public Health, 12, 201. https://doi.org/10.1186/1471-2458-12-201

[6] Brandlmeier, P. (1976) Multimorbidity among Elderly Patients in an Urban General Practice. $Z F A, 52,1269-1275$

[7] World Health Organization (2008) The World Health Report 2008-Primary Health Cared (Now More than Ever). The World Health Report, New York, 148.

[8] Badimon, L., Vilahur, G. and Padro, T. (2017) Systems Biology Approaches to Understand the Effects of Nutrition and Promote Health. British Pharmacological Society Journals, 83, 38-45. https://doi.org/10.1111/bcp.12965

[9] Li, X., Cai, L., Cui, W.L., et al. (2019) Association of Socioeconomic and Lifestyle Factors with Chronic Non-Communicable Diseases and Multimorbidity among the 
Elderly in Rural Southwest China. Journal of Public Health, 42, 239-246.

https://doi.org/10.1093/pubmed/fdz020

[10] QIAN Hansen, MA Ai-xia. Multi-morbidity status and its risk factors to multi-morbidity in middle-aged people in China. Chinese journal of drug evaluation, 2017(34), 6: 476-480

[11] Stevenson, J.C., Tsiligiannis, S. and Panay, N. (2019) Cardiovascular Risk in Perimenopausal Women. Current Vascular Pharmacology, 17, 591-594.

[12] Badimon, L., Chagas, P. and Chiva-Blanch, G. (2019) Diet and Cardiovascular Disease: Effects of Foods and Nutrients in Classical and Emerging Cardiovascular Risk Factors. Current Medicinal Chemistry, 26, 3639-3651.

[13] Stock, E.O., Ferrara, C.T., O’Connor, P.M., et al. (2018) Levels of Prebeta-1 High-Density Lipoprotein Are Elevated in 3 Phenotypes of Dyslipidemia. Journal of Clinical Lipidology, 12, 99-109. https://doi.org/10.1016/j.jacl.2017.11.001

[14] Zhang, R., Lu, Y., Zhang, S.-S., et al. (2019) Prevalence Pattern and Component Correlation of Chronic Disease Comorbidity among the Elderly in China. Chinese Journal of Public Health, 35, 1003-1005.

[15] Roeters van Lennep, J.E., Westerveld, H.T., Erkelens, D.W., et al. (2002) Risk Factors for Coronary Heart Disease: Implications of Gender. Cardiovascular Research, 53, 538-549. https://doi.org/10.1016/S0008-6363(01)00388-1 